\title{
Swelling Behaviour of Starch-g-Acrylic Acid Hydrogel and its Potential Application in Removal of Rhodamine B and Alkali Blue Dyes
}

\author{
S. Yahaya ${ }^{1 *}$, Z. I. S. G. Adiya ${ }^{1}$, S. S. Adamu², H. B. Bature ${ }^{1}$, I. B. Ibrahim² \\ ${ }^{1}$ Department of Pure and Applied Chemistry, Usmanu Danfodiyo University Sokoto, Nigeria. \\ ${ }^{2}$ Advanced Science Laboratory Complex, Usmanu Danfodiyo University Sokoto, Nigeria.
}

\begin{abstract}
Starch-g-acrylic acid hydrogel was prepared by free radical polymerization technique adopting potassium persulphate (KPS) as an initiator and N'N-methylenebisacrylamide (MBA) as a linking agent. The aim of the research is to inspect the potentials of starch-based hydrogel in remediating wastewater. Fourier Transform Infrared (FT-IR) spectroscopy was used to find the formation of hydrogel while Differential Scanning Calorimetry (DSC) and Scanning Electron Microscopy (SEM) were used for the characterization of the hydrogel. The FT-IR spectroscopy confirmed hydrogel formation. The DSC results showed that the generated hydrogel is thermally stable, and the SEM depicts a good porous site for dye adsorption. Batch adsorption for Rhodamine B (RDB) and Alkali blue (AB) dyes under the variation of contact time was 105 minutes for both dyes with percentage removal of 89.80 and $60.32 \%$, adsorbent dose was 0.4 and $0.8 \mathrm{~g}$ with percentage removal of 86.42 and $57.95 \%$, concentration was 50 and $30 \mathrm{ppm}$ with percentage removal of 67.01 and $77.18 \%$ and $\mathrm{pH}$ was 8 for both dyes with percentage removal of 77.43 and $79.13 \%$ as the optimum. The results indicates that acrylic acid monomer was efficiently grafted on the starch, and the adsorption method correlated with Freundlich isotherm equation. It was concluded that the starch-based hydrogel is an appropriate adsorbent and can be explored for industrial wastewater treatment.
\end{abstract}

KEYWORDS: Hydrogel, dyes, starch, acrylic acid, Fourier transform infrared, wastewater

[Received Feb. 6, 2021; Revised April 6, 2021; Accepted April, 18, 2021]

Print ISSN: 0189-9546 | Online ISSN: 2437-2110

\section{INTRODUCTION}

Synthetic dyes are common pollutants in industrial wastewater. They are stable, highly soluble and when they are discharged into water bodies, they present environmental hazards and potential dangers to health. Some of the azo dyes have been found to be carcinogenic and cause serious reproductive problems to humans ( $\mathrm{Yu}$ et al., 2020). Waterways have been used as dumping grounds for industrial effluents since the time of industrial revolution, industrial effluents have been discharged indiscriminately into waterways. the natural regeneration capacities of these waterways are being overwhelmed (Begum and Mahbub, 2013). Textile industries operations were among the most industrial activities carried out that discharge colored wastewater containing dyes that turn out to pollute the environment (Razi et al., 2017). The discharge of coloured effluents into the water bodies affect the nearby surroundings and become harmful to human and aquatic life (Rahman and Atker, 2016). With the growing utilization of artificial dyes in industrialization and urbanization, most waterbodies have been contaminated and many creatures are affected (Mahida and Patel, 2016).

Compared with other treatment procedures, such as flocculation, membrane filtration, advanced oxidation, ozonation, photocatalytic degradation, and biodegradation the adsorption technique is considered as prevailing over other wastewater treatment technology due to its benefits such as high efficiency, low cost, simple operation, and insensitive of toxic substances (Kunag et al., 2020).

Natural polymers have acquired interest as economical, and non-toxic materials. They are biodegradable, biocompatible can undergo chemical modifications. Starch is a biopolymer which can be extracted from many sources including but not limited to; wheat, tapioca, maize and potatoes (Benabid and Zouai, 2016). Starch is sometimes modified using chemical techniques by adding a minute amount of ionic or hydrophobic groups into the molecules of starch that can change the viscosity of the solution and affiliation behaviors (Ismail et al., 2013). The aim of the study is to prepare and characterize polymeric hydrogel of starch grafted with acrylic acid monomer and crosslinked with N'N-methylenebisacrylamide and its application in Rhodamine $\mathrm{B}$ and alkali blue dyes elimination from wastewaters. The objectives of the study are to:

i. extract starch from sweet potato and characterize it using FTIR

ii. prepare starch-g-acrylic acid hydrogel

iii. investigate the swelling capacity and characterize the hydrogel using FTIR, DSC and SEM 
iv. apply the hydrogel in the removal of Rhodamine B and Alkali blue dyes with the aid of adsorption technique from wastewaters.

\section{MATERIALS AND METHODS}

\section{A. Materials}

Acrylic acid (99\%, Qualikem), Initiator: Potassium Persulphate (KPS) $(99.9 \%$, Kermel), Crosslinking agent N'Nmethylenebisacrylamide (MBA) $(97 \%, \mathrm{BDH})$. Ethanol $(96 \%$, Sigma-Aldrich), hydrochloric acid (36.5\%, Sigma-Aldrich), Sodium hydroxide (98\%, Loba Chemi). Electronic weighing balance was used throughout for weighing of samples, UV spectral analysis was conducted using Perkin Elmer $\lambda-35 \mathrm{UV}$ spectrophotometer in Bayero University, Kano central laboratory complex. FTIR machine was Perkin Elmer spectrometer in the analytical laboratory of Bayero University, Kano. Scanning Electron Microscopy (Phenom proX model), differential scanning calorimetry (DSC 1 system-mettler Toledo) used are in National Research Institute for Chemical Technology (NARICT) Zaria, Kaduna state. All glass wares were washed and dried.

\section{B. Methods}

1) Hydrogel synthesis

The preparation of Starch-g-acrylic acid was done using the procedure proposed by Bhuyan et al., (2016). Starch (4 g), was poured into a three-neck round bottom flask which was placed inside water bath containing magnetic stirrer set at 200 rpm. The starch was stirred at a temperature of $60{ }^{\circ} \mathrm{C}$ for 20 minutes to form a gelatinized mixture. Acrylic acid $(5 \mathrm{ml}, 1$ M) was poured into the flask. MBA $(0.05 \mathrm{~g}, 0.1 \mathrm{M})$ was poured into the reaction container. Also, initiator, KPS $(0.05$ $\mathrm{g}, 0.1 \mathrm{M}$ ) was poured into the reaction container after 15 minutes and temperature was raised to $80{ }^{\circ} \mathrm{C}$ gradually for 2 hours under nitrogen atmosphere. The hydrogel formed was rinsed and washed with ethanol and dried in an oven at $50{ }^{\circ} \mathrm{C}$.

\section{2) Preparation of dye solutions}

Stock solutions (1000 ppm) of each RDB and AB dyes were prepared by dissolving $1.0 \mathrm{~g}$ in a beaker of distilled water until homogeneous solution was obtained. The resulting solution was quantitatively transferred to $1000 \mathrm{~cm}^{3}$ volumetric flask and diluted to the mark. Intermediate solutions of different concentrations were prepared by serial dilution of the stock solution.

\section{3) Batch adsorption}

The adsorption of RDB and $\mathrm{AB}$ dyes was done by of using starch-g-acrylic acid hydrogel using batch experiments according to the method stated by Ibrahim and Ahmed (2017). The impact of various parameters which includes agitation time $(15-150$ minutes), adsorbent dosage $(0.1-0.8 \mathrm{~g}$ for RDB and $0.1-1.0 \mathrm{~g}$ for $\mathrm{AB})$, initial dye concentration (10 $70 \mathrm{ppm}$ ) and initial dye $\mathrm{pH}(2-12)$ have been studied at consistent agitation pace of $200 \mathrm{rpm}$ at room temperature (25 ${ }^{\circ} \mathrm{C}$ ). The adsorption was carried out by mixing adsorbent in $100 \mathrm{~cm}^{3}$ Erlenmeyer flasks containing $10 \mathrm{~cm}^{3}$ of dye solutions of different concentrations. The percentage removal of RDB and $\mathrm{AB}$ dyes by starch-g-acrylic acid was calculated using Eq. (1).
$\% R=\frac{C o-C e}{C o} X 100$

where;

$R=$ Removal

Co $=$ Initial dye concentration

$\mathrm{Ce}=$ Residual dye concentration

The initial $\mathrm{pH}$ of the dye solutions was adjusted by adding drops of $0.1 \mathrm{M} \mathrm{HCl}$ or $0.1 \mathrm{M} \mathrm{NaOH}$ aqueous solutions.

$C 1 V 1=C 2 V 2$

where;

$C 1=$ Initial concentration of the dye

$C 2=$ Final concentration of the dye

$V 1=$ Initial volume of the dye

$V 2=$ Final volume of the dye

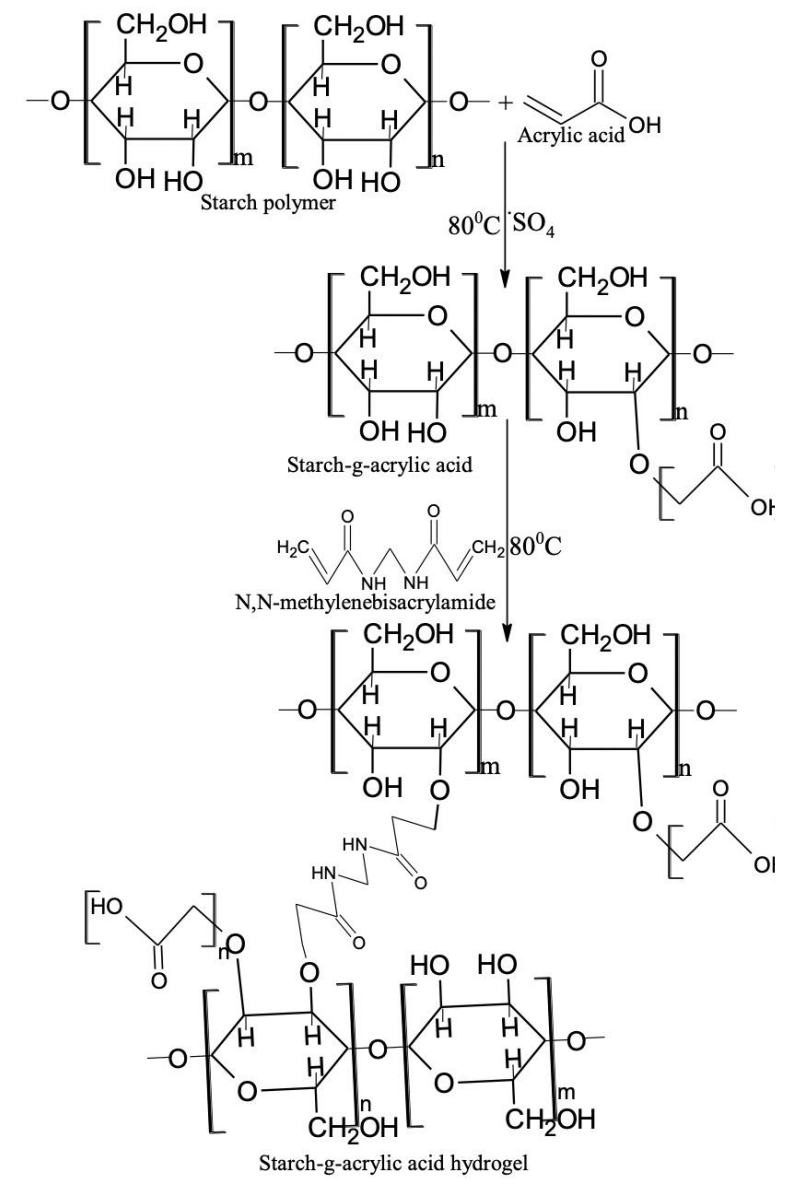

Scheme 1: Reaction scheme for the preparation of starch-g-acrylic acid.

\section{4) Swelling percentage of the hydrogel}

The percentage swelling study of the hydrogel was determined through immersing $0.5 \mathrm{~g}$ of dried hydrogel in a range $\mathrm{pH}$ of $1-14$ at $25{ }^{\circ} \mathrm{C}$ for 24 hours. Solutions of $\mathrm{pH} 1,2$, $3,4,5$, and 6 were prepared by adding $0.1 \mathrm{M} \mathrm{HCl}$ and solutions of $8,9,10,11,12,13$ and 14 were prepared by adding $0.1 \mathrm{M} \mathrm{NaOH}$. The $\mathrm{pH}$ was checked using JENWAY $\mathrm{pH}$ meter. After excess water was eliminated with filter paper, 
the weight of the swollen sample (hydrogel) was then calculated using Eq. (3).

$\%$ Swelling $=\frac{\mathrm{Wt}-\mathrm{Wo}}{\mathrm{Wo}} * 100$

where; $W o=$ initial weights of hydrogel and $\mathrm{Wt}=$ final weight of hydrogel<smiles>CCN(CC)c1ccc2c(-c3ccccc3C(=O)O)c3ccc(=[N+](CC)CC)cc-3oc2c1</smiles>

Scheme 2: Chemical structure of Rhodamine B dye.<smiles>C=C/C(=C\C)Nc1ccc(C(O)(c2ccc(Nc3ccc(S(=O)(=O)O[NH3+])cc3)cc2)c2ccc(N)c(C)c2)cc1</smiles>

Scheme 3: Chemical structure of Alkali blue dye.

\section{5) Fourier transform infrared spectroscopy (FTIR)}

Spectra of the monomer and the hydrogel were recorded on a CARRY 630 FTIR Agilent. All spectra (32 scans at $8.0 \mathrm{~cm}^{-1}$ resolution) were recorded at $25{ }^{\circ} \mathrm{C}$ and the spectra were at range of $4000-650 \mathrm{~cm}^{-1}$.

6) Scanning electron microscopy (SEM)

Surface morphology of the hydrogel before and after adsorption were examined using SEM. The morphologies of the prepared hydrogel were produced by scanning the surface of the samples with focused beam of electrons using Scanning Electron Microscopy Phenom proX model.

\section{7) Differential scanning calorimetry (DSC)}

Heat steadiness of the hydrogel was dictated using Differential Scanning Calorimetry (DSC). The sample was positioned on an aluminium crucible pressed and sealed. This was once observed by using heating, cooling and heating. The evaluation was carried out using DSC 1 Star System-Mettler Toledo instrument.

\section{RESULTS AND DISCUSSION}

\section{A. Preparation of Hydrogel}

FTIR spectra of starch-g-acrylic acid in Figure 1 exhibited a broad hydroxyl function at $3298 \mathrm{~cm}^{-1}(\mathrm{OH})$ from starch and an absorption at $2940 \mathrm{~cm}^{-1}$ due to $\mathrm{SP}^{3} \mathrm{C}-\mathrm{H}$ with another sharp absorption band at $1740 \mathrm{~cm}^{-1}$ corresponding to carbonyl of carboxylic acid. Absorption at $1186 \mathrm{~cm}^{-1}$ because of C-O confirmed the presence of carboxylic acid (Bhuyan 2016).

\section{B. Percentage Swelling}

The equilibrium swelling study indicated that the ionic hydrogel is sensitive to $\mathrm{pH}$. In acidic environment, the carboxylate groups were protonated, the reduced repulsion of anionic groups led to reduced swelling rate as shown in Figure 2.

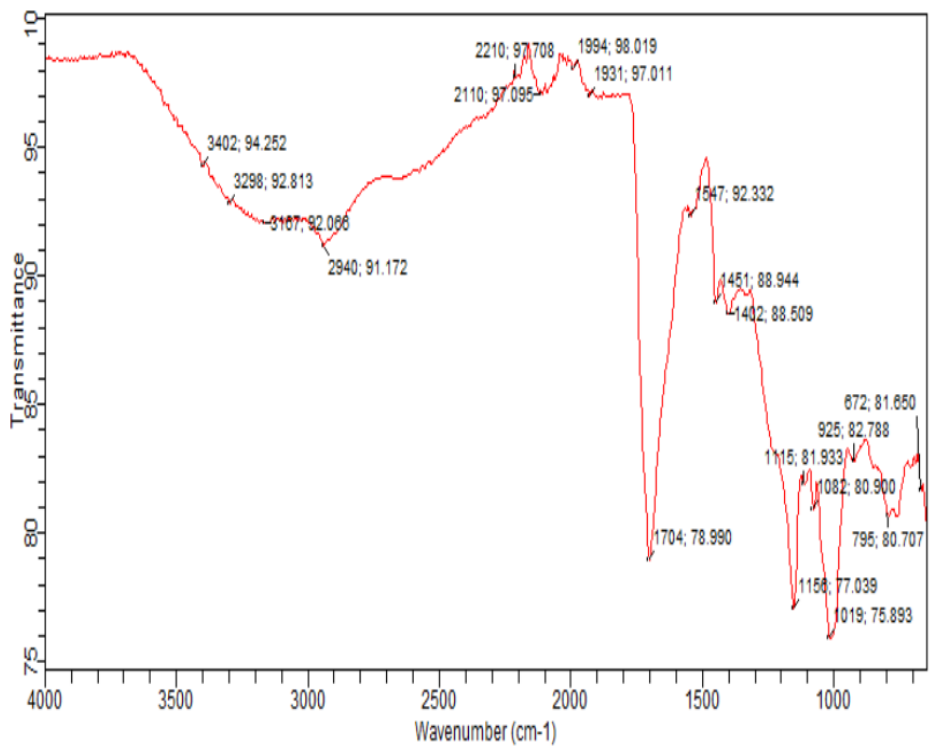

Figure 1: FTIR of starch-g-acrylic acid hydrogel.

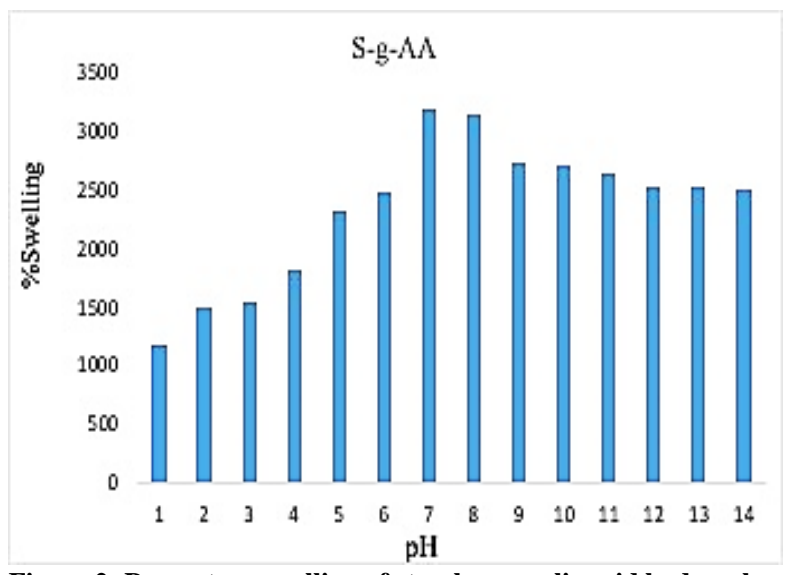

Figure 2: Percentage swelling of starch-g-acrylic acid hydrogel.

With the increase in $\mathrm{pH}$ the carboxyl groups of acrylic acids convert $-\mathrm{COOH}$ groups to $-\mathrm{COONa}$ groups with neutralization through $\mathrm{NaOH}$ in solution. The swelling loss in 
relatively basic solutions is due to charge screening impact of excess $\mathrm{Na}^{+}$in the swelling media, which prevent the carboxylate ions, also prevent effectual anion-anion repulsion (Sadeghi, 2011).

However, at $\mathrm{pH} \mathrm{7,} \mathrm{nearly} \mathrm{whole} \mathrm{ionization} \mathrm{of}-\mathrm{COOH}$ group results in widespread leisure due to repulsion amongst in a similar charged $\mathrm{COO}^{-}$groups present along the macromolecular chains (Figure 2). Moreover, ionization also causes an increase in ion osmotic pressure which results in increase in the swelling capacity of the hydrogel (Shaikh et al., 2015).

\section{Effect of Contact Time}

Contact time used are 15, 30, 45, 60, 5, 90, 105, 120, 135 and 150 minutes as shown in Figure 3 . The binding manner is going smoothly with increase in time and then reached the optimal. The remarkable removal for RDB and AB dyes by starch-g-acrylic acid hydrogel was 105 minutes percentage removal of 89.80 and $60.32 \%$ respectively as shown in Figure 3.

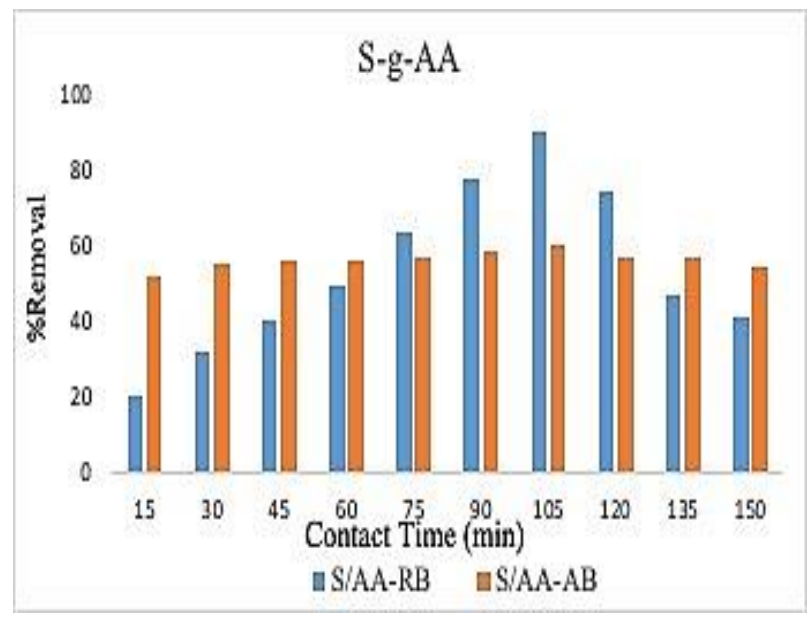

Figure 3: Effect of contact time on percentage removal.

The amount removal declines in RDB due to desorption which was due to the fact that the pores of the hydrogel were saturated with the dye. The adsorption of RDB dye was once more than that of $\mathrm{AB}$ dye which may be due to the difference in their physical and chemical properties (El-Arnaouty et al., 2015). Lower removal rate observed is due to a decrease in vacant sites of adsorbent and dye concentrations which show possible monolayer arrangements of $\mathrm{RDB}$ and $\mathrm{AB}$ dyes on the adsorbent surface (Patania et al., 2017).

\section{Effect of Adsorbent Dose}

Adsorbent dose was varied for starch-g-acrylic acid hydrogel for both RDB and $\mathrm{AB}$ dyes. Figure 4, shows that adsorption was increasing with increase in the available sites. The optimum removal of RDB and $\mathrm{AB}$ dyes were 0.4 and $0.8 \mathrm{~g}$ with percentage removal of 86.42 and $57.95 \%$ respectively as shown in Figure 4.The decrease in adsorptions is due to the ultimate vacant sites remaining unsaturated during the adsorption (Patel and Mahida, 2017).

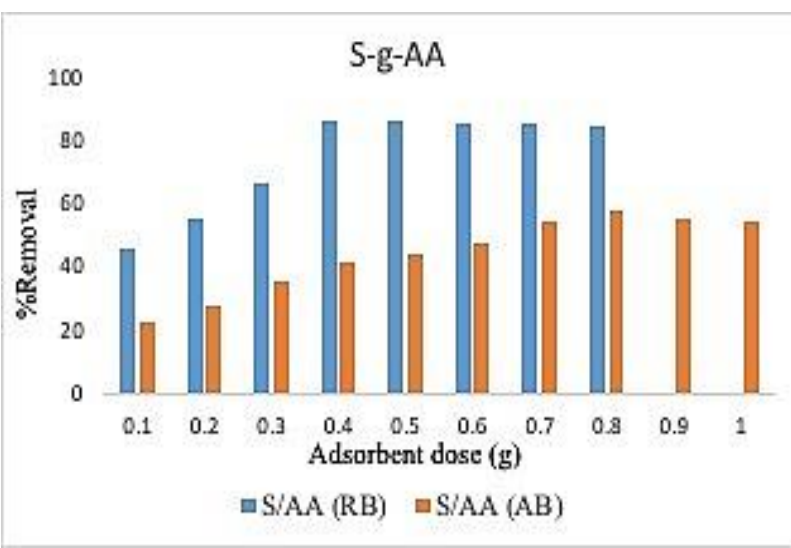

Figure 4: Effect of adsorbent dose on percentage removal.

\section{E. Effect of Concentration}

The effect of initial concentration of $\mathrm{RDB}$ and $\mathrm{AB}$ dyes studied on percentage removal have been in figure 5 , the adsorbent has many active sites which were continuously filled with increasing concentration of the dyes which resulted in the low percentage removal (Feng and Wen, 2017). Furthermore, the impact of concentration revealed that the

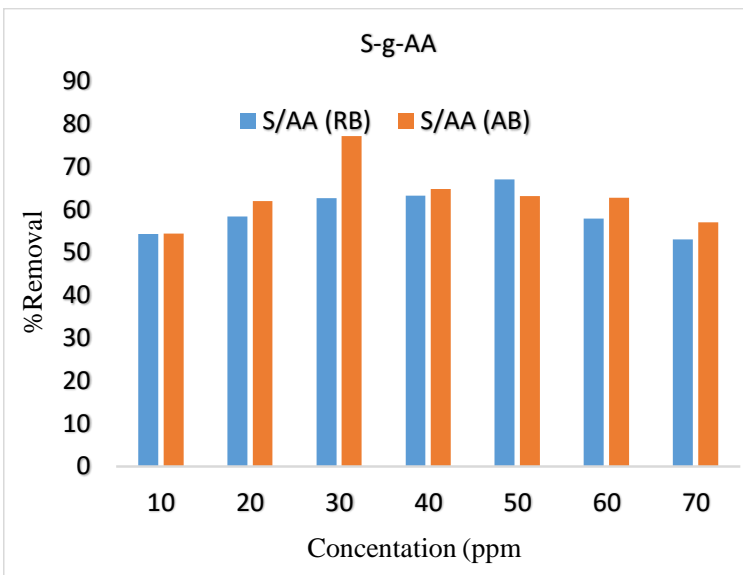

Figure 5: Effect of concentration on percentage removal.

percentage removal increased with increase in initial concentration of RDB and AB dyes (Song et al., 2016).

Moreover, as dye concentrations increases, the binding (electrostatic) forces for mass transfer additionally increases. At lower concentrations there might be unoccupied active sites on the adsorbent surfaces. At above the optimum of RDB and $\mathrm{AB}$ dyes concentrations, the site for adsorption of dye will be reduced (Patania et al., 2017).

\section{F. Effect of $p H$}

Lower adsorption of RDB and $\mathrm{AB}$ dyes at acidic $\mathrm{pH}$ as shown in Figure 6, is possibly because of the availability of many excess $\mathrm{H}^{+}$ions in competition with the cation groups on the dye for adsorption sites. At greater $\mathrm{pH}$, surface of the hydrogel particles might also get negatively charged, which enhances 
the positively charged dye cations via electrostatic forces of attraction (Ibrahim et al., 2016).

However, at basic $\mathrm{pH}$, $-\mathrm{COOH}$ groups ionizes to ${ }^{-\mathrm{COO}^{-}}$ ions and consequently dye adsorption occurs by a greater ionic interaction among positive charge on the dye molecules and negative charge of the $-\mathrm{COO}^{-}$groups present in the hydrogel. At acidic $\mathrm{pH}$, ionic interaction is relatively low because of the partial positive charge of - $\mathrm{COO}^{-}$groups on the hydrogel (Patel and Mahida, 2014).

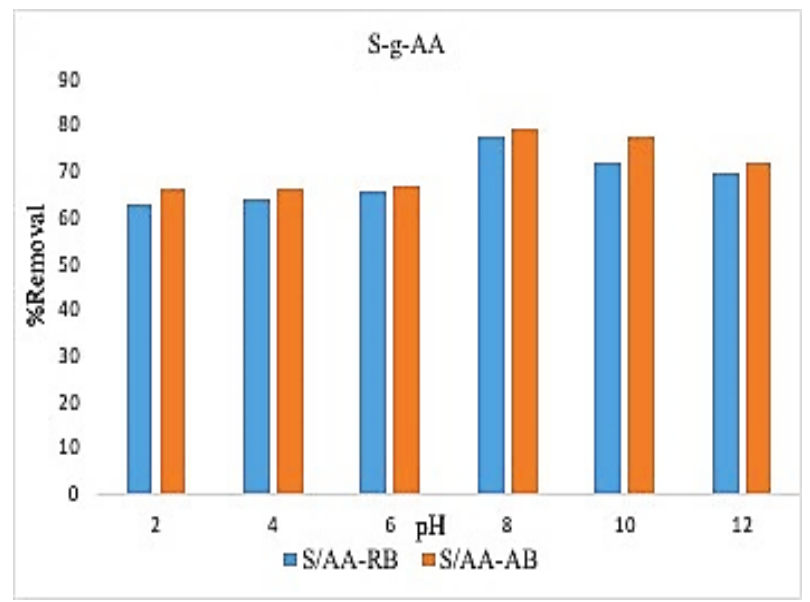

Figure 6: Effect of pH on percentage removal.

\section{G. Scanning Electron Microscopy (SEM)}

Figure 7 indicate SEM micrograph of the hydrogel. The hydrogel has a poriferous structure which is count on to be the place of water absorption/penetration and the interaction sites for RDB and $\mathrm{AB}$ dyes. Hydrogels water absorbency and its retention rate depend on porosity and pore size. Hence, one of the most important properties, which should be considered, is hydrogel microstructure morphologies. This porous micro structure brings about an increased surface area and capillary effect (Pourjavadi et al., 2007).

\section{H. Differential Scanning Calorimetry (DSC)}

Figure 8 showed the DSC thermograph of the hydrogel. The glass transition temperatures $\left(\mathrm{T}_{\mathrm{g}}\right)$ of starch-g-acrylic acid hydrogel was found to be $55^{\circ} \mathrm{C}$ with thermal stability of $152^{\circ} \mathrm{C}$. The grafted hydrogel was thermally stable. On the other hand, the starch not only strengthens the networks but also acts as a heat barrier, thus enhancing the thermal stability of the hydrogels (Mohana and Padmanabha, 2015).

\section{Adsorption Isotherms}

The Freundlich isotherm describes a heterogeneous surface with a non-uniform arrangement of adsorption and also describes the adsorption technique as "the ratio of the amount of solute adsorbed onto hydrogels to residual concentration is not same at different concentrations"'. The linear form is given in the equation 4

$\log q_{e}=\log K_{F}+1 / n \log C_{e}$

where, $\mathrm{K}_{\mathrm{F}}$ and $\mathrm{n}$ are the Freundlich constants that explains quantity of dye adsorbed per gram of adsorbent at equilibrium concentration and potency of the adsorption technique. It was evident that $\frac{1}{n}$ values between 0.1 and 1.0 show importance of adsorption and also, high $\mathrm{K}_{\mathrm{F}}$ proves a very good adsorption (Mahida and Patel, 2016).

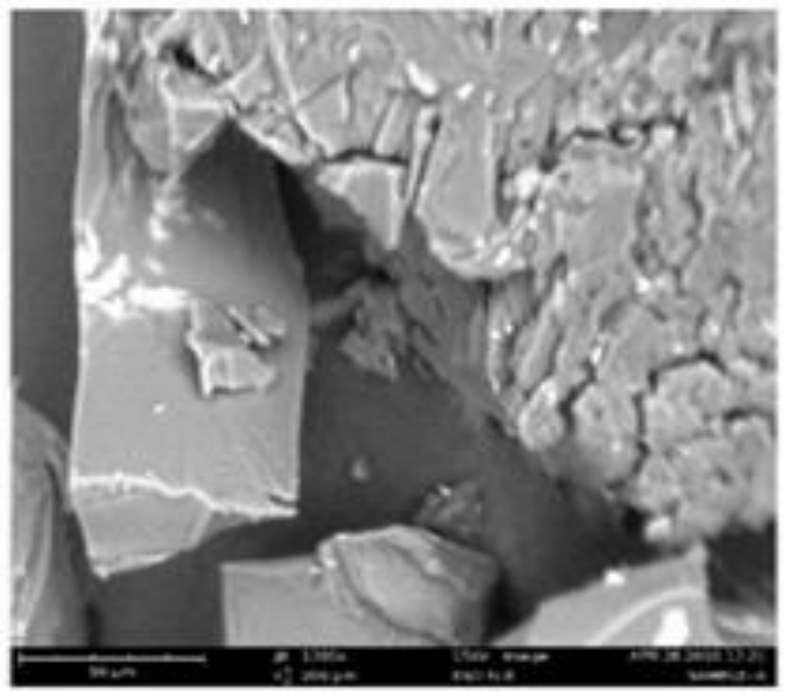

(a)

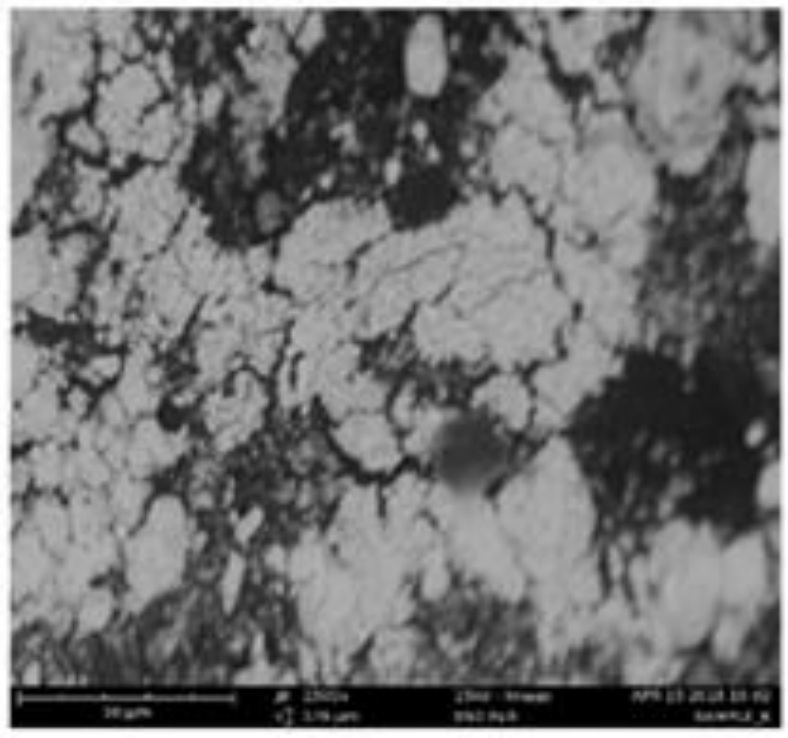

(b)

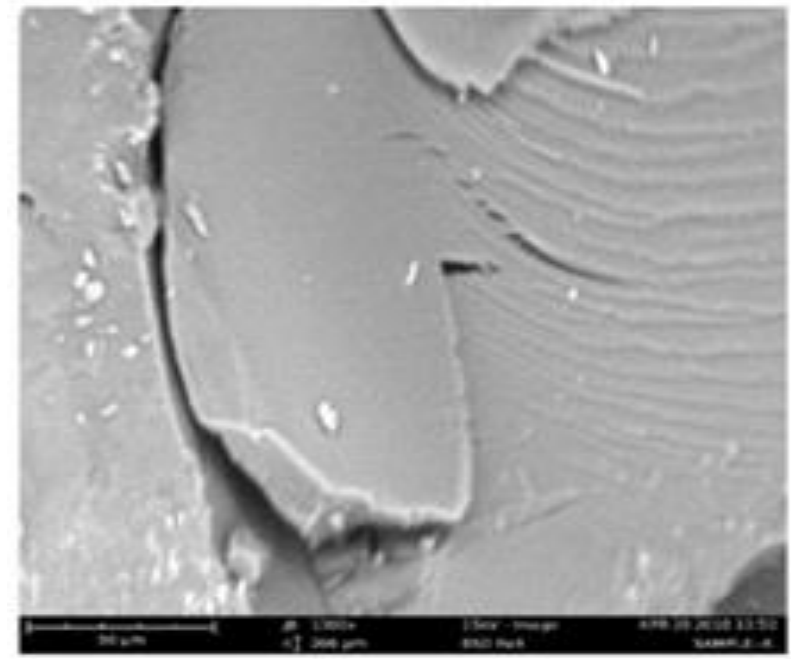

(c)

Figure 7: SEM images of (a) Starch-g-acrylic acid hydrogel (b) Adsorbed AB dye (c) Adsorbed RDB dye. 


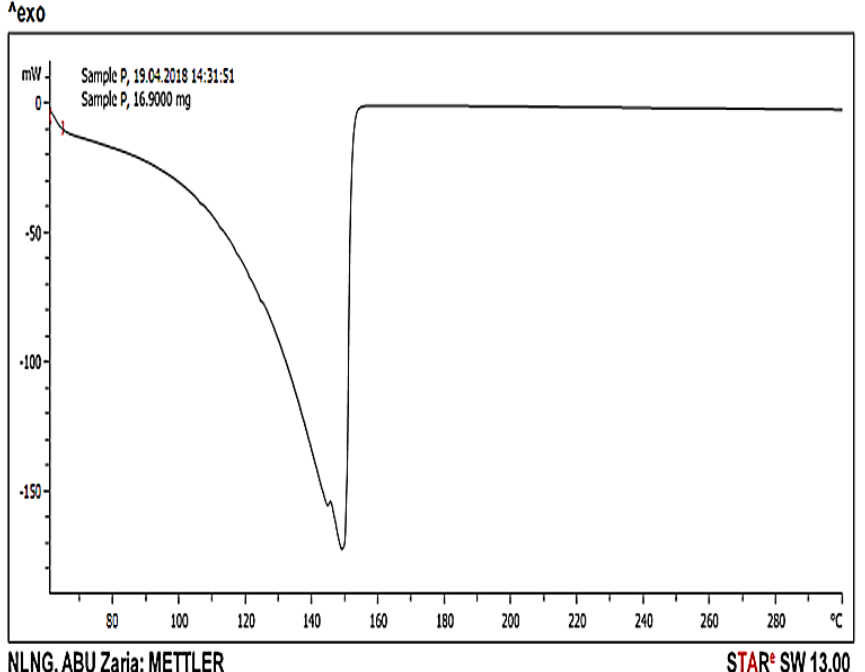

Figure 8: DSC of starch-g-acrylic acid hydrogel polymer.

The Langmuir model is used to describe the equilibrium between adsorbate and adsorbent system, where the adsorbate adsorption is limited to one molecular layer at or before a relative pressure of unity is reached. The linear form of the Langmuir isotherm is explained by Eq. (5).

$\mathrm{C}_{\mathrm{e}} / \mathrm{q}_{\mathrm{e}}=1 / \mathrm{K}_{\mathrm{L}} \mathrm{Q}_{\mathrm{m}}+\mathrm{C}_{\mathrm{e}} / \mathrm{q}_{\mathrm{m}}$

Here, $\mathrm{q}_{\mathrm{e}}$ is the quantity of dye adsorbed $(\mathrm{mg} / \mathrm{g}$ ) by the hydrogel, $\mathrm{q}_{\mathrm{m}}$ is the highest adsorption ability relating for Langmuir adsorption $(\mathrm{mg} / \mathrm{g})$, and $\mathrm{C}_{\mathrm{e}}$ is the residual concentration of dyes at equilibrium $(\mathrm{mg} / \mathrm{L})$ and $\mathrm{K}_{\mathrm{L}}$ is Langmuir adsorption constant (Abdel-Halim and Al-Hoqbani, 2015). All the correlation coefficients, $R^{2}$ values $(0.9106$ and 0.8255 ) are given in the graph chart, the $\mathrm{R}^{2}$ values of the Freundlich isotherm equation for all the adsorbents are highest, indicating that the Freundlich equation the best model to describe the adsorption of RDB and $\mathrm{AB}$ dyes on starch-gacrylic acid.

The nature of the adsorption process is explained by the dimensionless parameter RL defined by Eq. (6), which could be either unfavourable $(\mathrm{RL}>1)$, linear $(\mathrm{RL}=1)$, favourable $(0<\mathrm{RL}<1)$, or irreversible $(\mathrm{RL}=0)$.

$R L=\frac{1}{(1+\mathrm{KLC} 0)}$

where $C o$ is the initial dye concentration and $\mathrm{KL}$ is Langmuir constant.

A linear form of the Freundlich equation is generally expressed by Eq. (7).

$\log q e=\log K_{f}+1 / n_{f} \log C e$

where $q e$ is the amount of adsorbed dye at equilibrium $(\mathrm{mg} / \mathrm{g})$, $\mathrm{Ce}$ is the equilibrium concentration of the adsorbate $(\mathrm{mg} / \mathrm{L})$, $K_{f}$ is the Freundlich adsorption constant related to adsorption capacity of the adsorbent $(\mathrm{mg} / \mathrm{g})$, and $1 / n_{f}$ is the adsorption intensity.

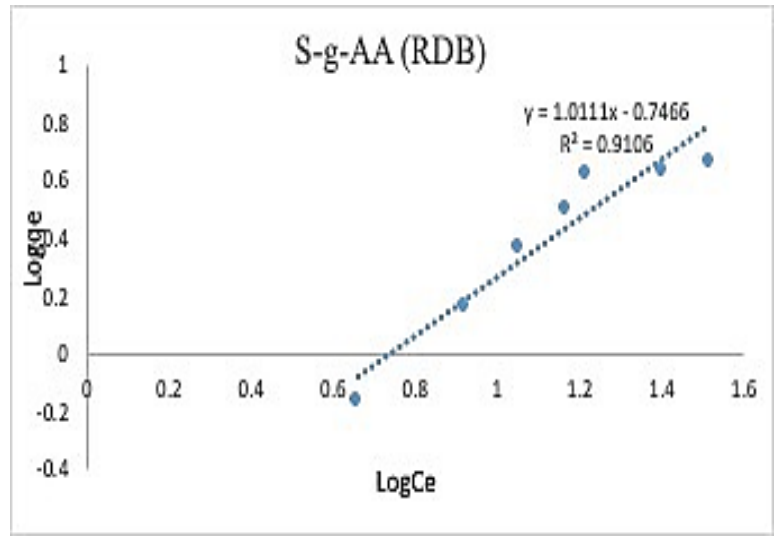

Figure 9: Freundlich isotherm for RDB dye using starch-g-acrylic acid hydrogel.

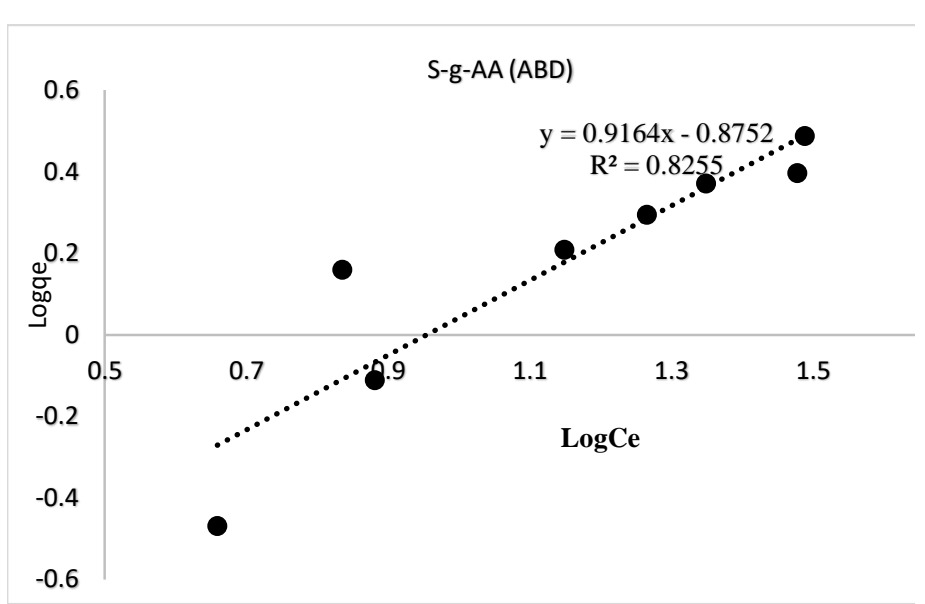

Figure 10: Freundlich isotherm for AB dye using starch-g-acrylic acid hydrogel.

Table 1: Adsorption isotherm.

\begin{tabular}{cccc}
\hline $\begin{array}{c}\text { Adsorption } \\
\text { parameters }\end{array}$ & Parameters & RBD & ABD \\
\hline Langmuir & $\mathrm{K}_{\mathrm{L}}\left(\mathrm{Lmg}^{-1}\right)$ & 0.0061 & 0.0059 \\
& $\mathrm{RL}$ & 0.7000 & 0.6800 \\
& $\mathrm{Q}_{\mathrm{m}}\left(\mathrm{mgg}^{-1}\right)$ & 32.4675 & 19.1200 \\
& $\mathrm{R}^{2}$ & 0.0702 & 0.0449 \\
& & & \\
Freundlich & $\mathrm{n}_{\mathrm{f}}$ & 0.9890 & 1.0912 \\
& $\mathrm{~K}_{\mathrm{f}}\left(\mathrm{mgg}^{-1}\right)$ & 0.1792 & 0.1332 \\
& $\mathrm{R}^{2}$ & 0.9106 & 0.8255 \\
\hline
\end{tabular}

\section{CONCLUSION}

Acrylic acid monomer was successfully grafted on starch through free radical polymerization technique adopting potassium persulphate (KPS) as an initiator and N'Nmethylenebisacrylamide (MBA) as a linking agent. The optimum conditions of the grafting was $\mathrm{pH} 7$ for maximum swelling and contact time of 105 minutes. The optimum concentration and adsorbent dose of RDB is $50 \mathrm{ppm}$ and $0.4 \mathrm{~g}$ respectively. Percentage removal of $67.01 \%$ and $86.42 \%$ were obtained from the optimum concentration and adsorbent dose of RDB respectively. On the other hand $30 \mathrm{ppm}$ is the 
optimum concentration for $\mathrm{AB}$ with $77.18 \%$ percentage removal and $0.8 \mathrm{~g}$ for adsorbent dose with percentage removal $57.95 \%$. FT-IR spectroscopy validate the hydrogel formation while DSC result revealed that the produced hydrogel is thermally stable, and the SEM images illustrates a good porous site for dye adsorption.

\section{REFERENCES}

Abdel-Halim, E. S. and Al-Hoqbani, A. A. (2015). Utilization of poly (acrylic acid)/cellulose graft copolymer for dye and heavy metal removal. Bioresources, 10 (2): 31123130 .

Begum, H. A. and Mahbub, M. K. (2013). Effectiveness of Carboxymethyl Cellulose for the Removal of Methylene Blue from Aqueous Solution. Dhaka University Journal of Science, 61 (2): 193-198.

Benabid, F. Z. And Zouai F. (2016). Natural Polymers: Cellulose, Chitin, Chitosan, Gelatin, Starch, Carrageenan, Xylan and Dextran. Algerian Journal of Natural Products, 4 (3): 348-357.

Bhuyan, M. M. D.; C. D. Nirmal, H. Kazuhiro, O. Hirotaka, H. Yoshiki, M. D. Mizanur Rahman, R. K. MohammadMizanur, and R. Nazia. (2016). Preparation of Potato Starch-Acrylic-Acid Hydrogels by Gamma Radiation and Their Application in Dye Adsorption. International Journal of Polymer Science Article ID 9867859.

Feng, K., and Wen, G. (2017). Absorbed $\mathrm{Pb}^{2+}$ and $\mathrm{Cd}^{2+}$ Ions in Water by Cross-Linked Starch Xanthate. International Journal of Polymer Science, 1-9.

Ibrahim, M. B. and Ahmed A. (2017). Adsorption of dyes onto activated water melon (Citrullus Lanatus). Bayero Journal of Pure and Applied Sciences 10(1): 606 - 614.

Ibrahim, M. B., and Ahmed, A. (2017). Adsorption of dyes onto activated water melon (Citrillus lanatus) rinds. Bayero Journal of Pure and Applied Sciences, 10 (1): 606-614.

Ismail, H.; I. Maryam and A. Zulkifli. (2012). StarchBased Hydrogels: Present Status and Applications. International Journal of Polymeric Materials and Polymeric Biomaterials, 62 (7): 411-420.
Kuang, Y.; Xiaoping Z., and Shaoqi Z. (2020). Adsorption of Methylene Blue in Water onto Activated Carbon by Surfactant Modification. Water, 12, 587; doi: 10.3390/w12020587.

Mahida, V. P. and Patel, M. P. (2017). Removal of some most hazardous cationic dyes using novel poly (NIPAAm/AA/N-allylisatin) nano-hydrogel. Arabian Journal of Chemistry, 9 (1): 430-442.

Mohana K. R. and Padmanabha M. R. (2001). Synthesis of Novel Super absorbing Copolymers for agricultural and horticultural applications 2001, Journal of Polymer International 50: 946-951

Pourjavadi A.; M. S. Amini-Fazl, and M. Ayyari. (2007). Optimization of synthetic conditions CMC-g-poly (acrylic acid)/Celite composite superabsorbent by Taguchi method and determination of its absorbency under load. eXPRESS Polymer Letters, 1 (8); 488-494

Rahman, F. B. A., and Akter, M. (2016). Removal of Dyes Form Textile Wastewater by Adsorption using Shrimp Shell. International Journal of Waste Resources, 6 (3): 1-5.

Razi M.; A. Mohammad, N. Mimi, M. H. Attahirah, and H. Rafidah. (2017). Factors Affecting Textile Dye Removal Using Adsorbent From Activated Carbon: A Review. MATEC Web of Conferences, 103: 1-14.

Sadeghi, M. (2011). Preparation of starch-g-poly (acrylic acid-co-2-hydroxy ethyl methacrylate) as a potential $\mathrm{pH}$ sensitive hydrogel-based drug delivery system. Turk J Chem, 35: 723 - 733 .

Shaikh, M.; M. D. Mateen, S. Gramopadhye, A. Anand, W. Shrikant, V. Lonikar. (2015). Starch-Acrylic Acid Hydrogel: Preparation, Characterization and Drug Release Study. World Journal of Pharmacy and Pharmaceutical Sciences, 4 (7): 942-954.

Song X.; C. Fangeng, and L. Shangjun. (2016). A Lignin containing hemicellulose-based hydrogel and its absorption behavior. Bioresources, 11 (3); 6378-6392.

Yu, J.; Z. Aiyi, H. Wenting and L. Bin. (2020). Adsorption of Mixed Dye System with Cetyltrimethylammonium Bromide Modified Sepiolite: Characterization, Performance, Kinetics and Thermodynamics. Water, 12, 981; doi: 10.3390/w12040981. 